\title{
Optimization of growth of InGaAs/InP quantum wells using photoluminescence and secondary ion mass spectrometry ${ }^{\dagger}$
}

\author{
S BHUNIA, P BANERJI, T K CHAUDHURI, A R HALDAR, D N BOSE*, Y APARNA, \\ M B CHETTRI ${ }^{\ddagger}$ and B R CHAKRABORTY \\ Advanced Technology Centre, Indian Institute of Technology, Kharagpur 721 302, India \\ ${ }^{\ddagger}$ National Physical Laboratory, New Delhi 110 012, India
}

\begin{abstract}
InGaAs/InP quantum wells of widths varying from $19 \AA$ A to $150 \AA$ have been grown by MOVPE and the growth temperature optimized using photoluminescence and SIMS. It was thus found that for a $78 \AA$ well the lowest PL linewidth of $12.7 \mathrm{meV}$ at $12 \mathrm{~K}$ was obtained for growth at $625^{\circ} \mathrm{C}$. SIMS also showed sharpest interfaces for this temperature compared with growth at $610^{\circ} \mathrm{C}$ and $640^{\circ} \mathrm{C}$. The well widths determined from PL energies were in good agreement with a growth rate of $8.25 \AA / s$. However, while the barrier widths of $150 \AA$ were in agreement with SIMS results, the well widths from SIMS were found to be much larger, due to a lower sputtering rate of InGaAs compared with InP. Quantitative comparison was made assuming the presence of InAsP and InGaAsP interface layers on either side of the wells and the relative sputtering rates determined.
\end{abstract}

Keywords. InGaAs/InP quantum wells; PL; SIMS.

\section{Introduction}

The ternary alloy $\operatorname{In}_{1-x} \mathrm{Ga}_{x} \mathrm{As}$ is important as it can be lattice-matched to InP for $x=0.47$ and, having a band-gap of $0.75 \mathrm{eV}$ at $300 \mathrm{~K}$, is suitable for fibre-optic applications. Considerable work on the growth of InGaAs quantum wells on InP has been carried out as reported by Razeghi (1989a) and Stringfellow (1989). The great advantage of such quantum wells is that emission can be obtained at energies varying from $1.10 \mathrm{eV}$ to $0.75 \mathrm{eV}$ depending on the well width without changing composition. The better-known GaAs/AlGaAs system has the advantage of being intrinsically lattice-matched for all $\mathrm{Al}$ concentrations and has a higher conduction band offset $\Delta E_{\mathrm{c}}$ giving better carrier confinement. However, due to higher band-gap this system is not suitable for operation between $1.3-1.55 \mu \mathrm{m}$ as required for low-loss fibre-optic communication.

In this paper we report the growth of InGaAs/InP quantum wells by MOVPE with thicknesses down to $19 \AA$ giving PL emission near $1 \cdot 10 \mathrm{eV}$ at $12 \mathrm{~K}$. The layers have been characterized by double crystal X-ray diffractometry (DCXRD) to give the triple bilayer period of $717 \AA$ (calc. value $735 \AA$ ) and also by SIMS to estimate the well and barrier widths directly. The determination of such narrow well widths by SIMS has rarely been reported before, most of the work being limited to thicknesses > $100 \AA$ as given by Razeghi et al (1989b).

\footnotetext{
*Author for correspondence

${ }^{\dagger}$ Paper presented at the 5th IUMRS ICA98, October 1998, Bangalore
}

\section{Experimental}

A conventional atmospheric pressure MOVPE system (Thomas Swan U.K.) was used having a horizontal watercooled reactor with graphite susceptor heated by an IR lamp. The system had a fast-switching manifold with full computer control and an Epison controller for TMI. The reactants used were trimethyl indium (TMI) kept at $+20^{\circ} \mathrm{C}$, trimethyl gallium (TMG) at $10^{\circ} \mathrm{C}$, together with arsine and phosphine. Typical gas flow rates were $4 \mathrm{l} / \mathrm{min}$. $\mathrm{H}_{2}$ carrier passed through a Pd-purifier, $6 \cdot 3 \mathrm{sccm}$ TMG, $92 \mathrm{sccm}$ TMI, $140 \mathrm{sccm} \mathrm{PH}_{3}$ and $70 \mathrm{sccm} \mathrm{AsH}$. These flow rates were arrived at through repeated experiments followed by DXRD and optical absorption studies to obtain the condition $x=0.43$ for lattice-matching. Substrates used were $\mathrm{Sn}$ doped InP oriented $2^{\circ}$ off (100). The estimated growth rate was $8.25 \AA / s$. For standardization 4 wells with widths of $19 \AA, 38 \AA, 78 \AA$ and $150 \AA$ were grown with $150 \AA$ barriers of InP followed by a $0.2 \mu \mathrm{m}$ InP capping layer. PL from such layers was studied between 12-300 K using an Ar ion laser (488 nm), 0.65 m McPherson monochromator and cooled InGaAs detector. The variation of PL peak energy with decrease in well width was in excellent agreement with calculations. Typical PL spectra from 3 wells at $12 \mathrm{~K}$ is shown in figure 1 . For laser emission at $1.55 \mu \mathrm{m}, 4$ identical InGaAs wells $78 \AA$ in width with $300 \AA$ InP barriers were grown. To optimize growth temperature, the PL linewidths from such wells were measured for growth at $610^{\circ} \mathrm{C}, 625^{\circ} \mathrm{C}$ and $640^{\circ} \mathrm{C}$. These were found to be $15 \mathrm{meV}, 12.7 \mathrm{meV}$ and $15.7 \mathrm{meV}$ respectively, clearly showing that the sharpest wells were obtained for growth at $625^{\circ} \mathrm{C}$. 
SIMS studies were then carried out on these structures to determine the nature of the interfaces and well widths. An inclined $\mathrm{O}_{2}^{-}$ion beam was used at $7 \mathrm{KeV}$ with beam current of $10^{-8} \mathrm{~A}$, the area examined being typically 150 $400 \mu \mathrm{m}^{2}$. The average sputtering rate was kept as low as $1 \AA \mathrm{s}$, this being determined by measurement of the crater depth by a stylus after sputtering for a given period. The depth profile of the structure grown at $625^{\circ} \mathrm{C}$ is given in figure 2 clearly showing 4 wells of increasing width.

Similar SIMS studies for growth at $610^{\circ} \mathrm{C}$ showed less sharp wells while for $640^{\circ} \mathrm{C}$ interdiffusion between wells was clearly evident. The well thicknesses were estimated from the variation in concentration of $\mathrm{P}$ between $10 \%$ to $90 \%$. It was thus found that the widths of the $150 \AA$ barriers and InP capping layer were in good agreement with growth parameters but the well widths were found to be much larger, the difference increasing with lower width. It was considered that this could be due to difference in sputtering rate between InGaAs and InP. Further due to remanence time of the gases in the reactor while switching and the larger sticking coefficient of As compared with $\mathrm{P}$, atomically abrupt interfaces are not expected. The exact nature of the interfaces can be modelled as shown in figure 3, consisting of a structure as follows: InP-InAsPInGaAs-InGaAsP-InP. The interfacial layers InAsP and InGaAsP are also expected to have different sputtering rates.

The well widths $w$ determined from PL which are in good agreement with growth parameters can thus be related to the values $S$ from SIMS by the relation:

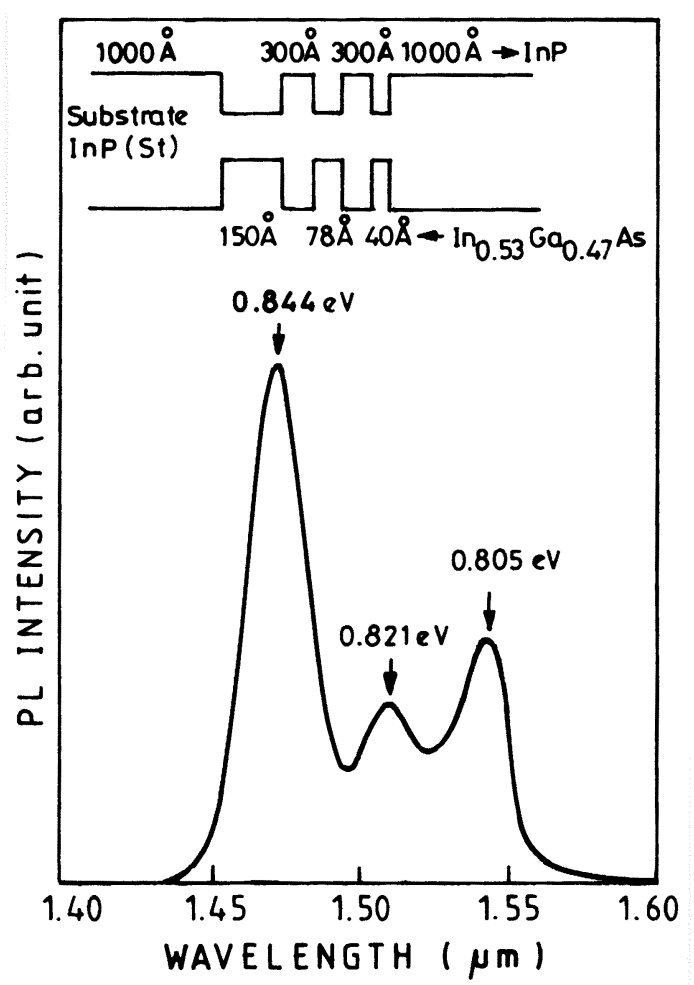

Figure 1. PL spectrum of MQW.

$$
S=I_{1} \beta_{1}+w \alpha+I_{2} \beta_{2}
$$

where $I_{1}$ and $I_{2}$ are the thicknesses of the 2 interfacial layers with relative sputtering rates, $\beta_{1}$ and $\beta_{2}, w$ the width of the InGaAs quantum well with relative sputtering rate $\alpha$ with respect to InP. Since 4 different values of well widths are available it is possible to set up 4 equations using the following values of $S$ and $w$ as found experimentally: $S_{1}=7 \mathrm{~nm}, \quad w_{1}=1.9 \mathrm{~nm} ; S_{2}=11 \mathrm{~nm}, \quad w_{2}=3.9 \mathrm{~nm}$; $S_{3}=17 \mathrm{~nm}, w_{2}=7.8 \mathrm{~nm}$ and $S_{4}=33 \mathrm{~nm}, w_{2}=15 \mathrm{~nm}$. For simplicity we can assume $I_{1}=I_{2}=I$ and $\beta_{1}=\beta_{2}=\beta$. If we take $I=2$ monolayers $=0.586 \mathrm{~nm}$, we find $\alpha=1.82$ and $\beta=3.73$, where $\alpha=$ sputtering rate of InP/InGaAs and $\beta=$ sputtering rate of $\mathrm{InP} / \mathrm{InGaAsP}$.

It is expected that the ternaries and quaternaries will have lower sputtering rates compared with InP. A controlled experiment was next carried out with relatively thick layers of InGaAs and InP, sputtered under identical conditions for the same time. It was thus found that

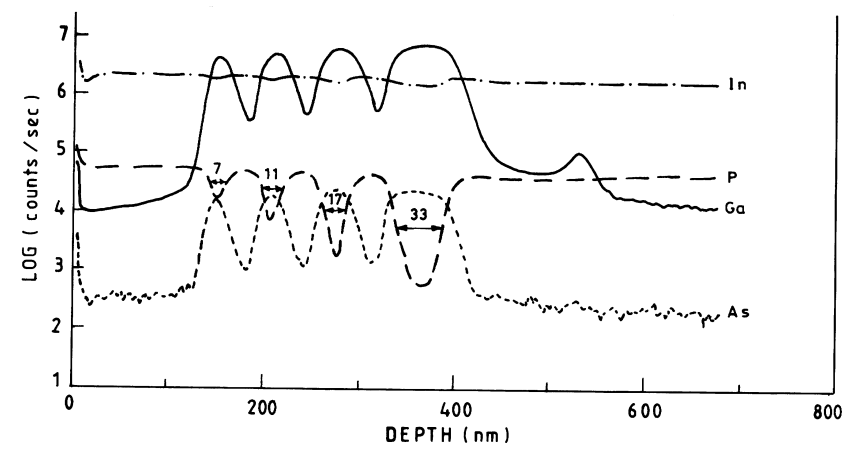

Figure 2. Typical SIMS profile of the grown structure.
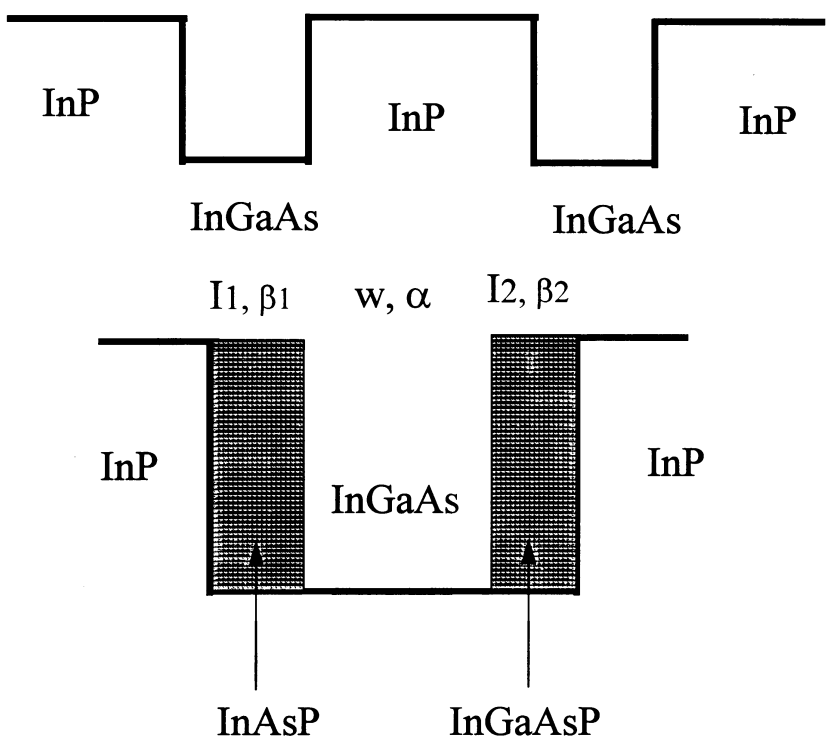

Figure 3. Interfacial structure of the MQW. 
the sputtering rate of InP was 1.4 times larger than that of InGaAs. This compares reasonably well with the value of $\alpha=1.82$ calculated above. Further studies on the interfacial layers are to be carried out to validate the model.

\section{Conclusions}

PL and SIMS studies have been used to characterize MOVPE grown InGaAs/InP quantum wells and quantitatively determine well widths. Differences in estimation are attributed to differences in sputtering rates between InGaAs and InP during SIMS and also due to the presence of interfacial layers.

\section{Acknowledgements}

The authors are grateful to the National Laser Programme of the Department of Atomic Energy for funding this project on Semiconductor Lasers, the Director, IIT Kharagpur and the Director, National Physical Laboratory, New Delhi, for the work on SIMS characterization.

\section{References}

Razeghi M 1989a The MOCVD challenge (Bristol: Adam Hilger) Vol. 1

Razeghi M 1989b EIT workshop on photonics (Vienna: Banca Popolare di Verona) p. 49

Stringfellow G B 1989 Organometallic vapour-phase epitaxy (Boston: Academic) 